\title{
Aqueous alteration without initial water: possibility of organic-induced hydration of anhydrous silicates in meteorite parent bodies
}

Naoki Hirakawa', Yoko Kebukawa ${ }^{1 *}\left(\mathbb{0}\right.$, Yoshihiro Furukawa ${ }^{2}$, Masashi Kondo $^{3}$, Hideyuki Nakano ${ }^{4}$ and Kensei Kobayashi ${ }^{1}$

\begin{abstract}
Early evolution of Solar System small bodies proceeded through interactions of mineral and water. Melting of water ice accreted with mineral particles to the parent body results in the formation of secondary minerals, the so-called aqueous alteration. Formation of phyllosilicates from anhydrous silicates is a typical alteration effect recorded in primitive meteorites. In addition to mineral and water, organic matter could have been also a significant component in meteorite parent bodies. However, the role of organic matter in the alteration of silicates is not well understood. We conducted a heating experiment of anhydrous silicate (olivine) with a mixture of organic compounds which simulated primordial organic matter in the Solar System. Dissolution and precipitation features were confirmed on the olivine surface after heating at $300^{\circ} \mathrm{C}$ for 10 days, and proto-phyllosilicates were formed in the precipitation area. Magnesite was also detected as concomitant mineral phase. These minerals could be the evidence of aqueous alteration and carbonation of olivine induced by water generated through decomposition of the organic compounds with hydroxy groups. Our result showed that the in situ formation of hydrated silicates through a mineral-organic interaction without the initial presence of water. It further implies that formation of phyllosilicates on the olivine surface in contact with organic matter can occur in meteorite parent bodies which formed inside the $\mathrm{H}_{2} \mathrm{O}$ snow line but accreted with organic matter, initially without water. Water formed through decomposition of organic matter could be one candidate for hydrous silicate formation, for example, in ordinary chondrites from S-type asteroids inside the $\mathrm{H}_{2} \mathrm{O}$ snow line. Although the origin of water in ordinary chondrites is under debate, water generation from organic matter may also explain the D-rich water in ordinary chondrites because primordial organic matter is known to be $D$ rich.
\end{abstract}

Keywords: Organic matter, Phyllosilicates, Water, Chondrites, Small bodies

\section{Introduction}

Minerals, water, and organic matter are the initial building blocks of our Solar System. Evolution of the earlystage Solar System proceeded with their interactions.

\footnotetext{
*Correspondence: kebukawa@ynu.ac.jp

${ }^{1}$ Graduate School of Engineering Science, Yokohama National University,

79-5 Tokiwadai, Hodogaya-ku, Yokohama 240-8501, Japan

Full list of author information is available at the end of the article
}

Following accretion to planetesimals, $\mathrm{H}_{2} \mathrm{O}$ ice melted by the heating mostly due to the decay of short-lived radioactive nuclides (Brearley 2006; Trigo-Rodríguez et al. 2019). The water fluid contributed to the aqueous alteration of minerals with distributing and migrating some elements (Brearley 2006; King et al. 2017). Alteration of anhydrate silicates results in the formation of phyllosilicates. Phyllosilicates are abundant in CI, CM, and $\mathrm{CR}$ chondrites; thus, these chondrites experience 
strong aqueous activities (Brearley 2006). Phyllosilicates also exist in some "dry" chondrites, such as CV, $\mathrm{CO}$, and unequilibrated ordinary chondrites (Buseck and Hua 1993; Brearley 2006), although they are much less abundant compared with $\mathrm{CI}$ and $\mathrm{CM}$ chondrites. These phyllosilicates in such dry chondrites may be evidence of water in their parent bodies (Bischoff 1998); however, the origin of the water in these chondrites is not well understood. These "dry" chondrites are known to be thermally metamorphosed in their parent bodies mainly due to the decay of short-lived nuclides (Huss et al. 2006). Thermal metamorphism by the heating could gradually affect the nature of meteorites. For example, the least metamorphosed chondrites (unequilibrated ordinary chondrites) experienced slight heating, such as Semarkona meteorite (LL3.0, $\sim 260^{\circ} \mathrm{C}$, Alexander et al. 1989), Vigarano (CV3, 300-400 ${ }^{\circ} \mathrm{C}$, Tomeoka and Tanimura 2000; Huss 2006), and Kainsaz (CO3.2, $300{ }^{\circ} \mathrm{C}$, Huss et al. 2006). Although these temperatures would result in low-degree effects on petrology or mineralogy, they could have significant influence on the structure and composition of organic matter in meteorites via various chemical reactions. Additionally, impact-induced heating could be another heat source. Impact compactions could occur during the formation of small bodies prior to most of aqueous alteration (Trigo-Rodríguez et al 2006; Beitz et al. 2016). Some carbonaceous chondrites also show post-alteration heating shown by evidences, such as dehydration of phyllosilicates, recrystallization of olivine, carbonization, and graphitization of organic matter (Kitajima et al. 2002; Nakamura 2005; Rubin et al. 2007; Nakato et al. 2008; Quirico et al. 2018). Hydrous minerals could remain in weakly heated chondrites $\left(<250{ }^{\circ} \mathrm{C}\right.$; Nakamura 2005).

In terms of interactions among minerals, water, and organic matter, the role of organic matter for alteration of minerals is not well understood. Recent studies suggested that minerals act as catalysts for the formation and evolution of organic matter (Pearson et al. 2002; Kebukawa et al. 2010; Yamashita and Naraoka 2014; Le Guillou et al. 2014; Fuchida et al. 2017; Rotelli et al. 2016; Vinogradoff et al. 2020a, b; Hirakawa et al. 2020 in press). Chemical reactions of organic matter are frequently accompanied by simultaneous generation of by-products. Nakano et al. (2020) performed heating experiments of organic mixtures up to $400{ }^{\circ} \mathrm{C}$, which simulated the evolution of primordial organic matter in meteorite parent bodies, and they found various by-products, including $\mathrm{CO}, \mathrm{CO}_{2}$, and $\mathrm{H}_{2} \mathrm{O}$ during the experiments. These compounds in turn could have influence on mineral alterations.

In this study, we performed a heating experiment of an anhydrous silicate (olivine) with an organic mixture simulating thermal metamorphism in meteorite parent bodies. The reaction products were analyzed using X-ray diffraction (XRD), secondary electron microscopy with energy-dispersive X-ray spectroscopy (SEM/EDS), and transmission electron microscopy with energy-dispersive $\mathrm{X}$-ray spectroscopy (TEM/EDS). Through this study, we showed that minerals could be altered by organic matter in meteorite parent bodies without the initial presence of water.

\section{Experimental \\ Starting materials}

In this study, olivine was used as a typical anhydrous silicate in chondritic meteorites. San Carlos olivine powder (Fo91) was heated in an autoclave (Tama-Seiki) with a precometary-organic-matter analog (Additional file 1: Table S1, Nakano et al. 2002, 2020), which simulated the primordial organic matter accreted to meteorite parent bodies before thermal metamorphism. The olivine powder, the initial grain size of which was $<200 \mu \mathrm{m}$, was ground before the experiments using an agate mortar to obtain a typical grain diameter of $<50 \mu \mathrm{m}$. The organic mixture was prepared following the methods of Kouchi et al. (2002), Nakano et al. (2002, 2003, 2020), and Hirakawa et al. (in press).

\section{Heating experiment}

For the heating experiment, $0.2 \mathrm{~g}$ of ground olivine powder with $1.0 \mathrm{~g}$ of organic mixture was sealed in a stainless steel Swagelok tube fitting union $(3 / 8$ in.) with 316 stainless steel plugs $\left(3 / 8\right.$ in., $\left.3.0 \mathrm{~cm}^{3}\right)$ under $\mathrm{N}_{2}$ gas atmosphere. The tube fitting was placed in an autoclave (Tama-Seiki) and then heated at $300^{\circ} \mathrm{C}$ for 10 days (Additional file 1: Figure S1). After the tube fitting was cooled, the experimental product was recovered. The product was rinsed with hexane $(3 \mathrm{~mL})$ and methanol $(3 \mathrm{~mL})$ to eliminate the organic matter from the surface of the olivine. To estimate the amount of water generated in heated product, a heating experiment without olivine was performed. Details are described in Additional file.

\section{Characterization techniques $X R D$}

The initial olivine and experimental product rinsed with hexane and methanol were analyzed by powder XRD using a SmartLab diffractometer with a Hypix3000 detector (Rigaku, Ltd.) at $40 \mathrm{kV}$ and $45 \mathrm{~mA}$ by $\mathrm{Cu}$ $\mathrm{K} \alpha$ radiation with a scan speed of $5.0 \% \mathrm{~min}$ and a resolution of 0.01 . Identification of the mineral phase was performed using SmartLab Studio II by searching the diffraction patterns from International Center for Diffraction Data (ICDD) database through the Hanawalt search method. 


\section{SEM/EDS}

Grain size, morphology, and elemental composition of the experimental products were characterized using a scanning electron microscope (JSM-6510LA, JEOL) equipped with an energy-dispersive X-ray spectrometer (JED-2300, JEOL). Grains were fixed on a $10-\mathrm{mm}$ brass stub with resin and were coated by Au sputtering. All grains were observed by secondary electron imaging at $15 \mathrm{kV}$. An elemental analysis was conducted by EDS at 20 $\mathrm{kV}$.

\section{Focused ion beam (FIB) processing}

Focused ion beam preparations were performed with an NX2000 (Hitachi High-Tech Global) at the Japan Aerospace Exploration Agency. First, the surface of the target area in an olivine grain on an SEM stub was covered with a carbon deposition layer. Three sides of the target area were milled on the surface of the SEM stub $(\sim 10 \mu \mathrm{m}$ depth). After the bottom edge was cut, the section was suspended by a cantilever and then attached to a silicon nanomesh. The sample was thinned to the thickness that allows electron transparency $(<100 \mathrm{~nm})$ using successively lowered $\mathrm{Ga}^{+}$ion beam currents of $12 \mathrm{nA}, 1.5 \mathrm{nA}$, $280 \mathrm{pA}$, and $100 \mathrm{pA}$ at $30 \mathrm{kV}$, and final polishing was done using a current of $20 \mathrm{pA}$ at $10 \mathrm{kV}$ and $20 \mathrm{pA}$ at $5 \mathrm{kV}$ of ion energy.

\section{TEM/EDS}

FIB thin sections were analyzed using TEM (JEM2100F, JEOL) equipped with EDS (JED-2300T, JEOL) at Yokohama National University and Tohoku University.
High-resolution images were obtained at $200 \mathrm{kV}$. EDS spectra were accumulated for approximately $1 \mathrm{~h}$.

\section{Results \\ XRD}

While the bulk structure of olivine did not change significantly after heating with organic mixture, there were some evidences of mineral replacement in the XRD pattern of the olivine after the experiment (Fig. 1). A wide loose curve from 15 to $50^{\circ}$ in the baseline could indicate the existence of amorphous phase with crystalline olivine. Magnesite has strong peaks at $32.5^{\circ}, 43^{\circ}$, and $54^{\circ}$ (Lafey et al. 2014; Ulrich et al. 2014); thus, small peaks around $43^{\circ}$ and $54^{\circ}$ were diffraction from magnesite minerals, which are secondary minerals formed during the heating of olivine with organic matter. The peak at $32.5^{\circ}$ could be overlapping with olivine. Peaks of olivine and magnesite are indicated in Fig. 1 . Small peaks at $7^{\circ}$, $19^{\circ}$, and $25^{\circ}$ possibly indicated the formation of phyllosilicates, although the exact mineral species could not be identified. The other unidentified peaks could be impurities originally contained in natural olivine samples.

\section{SEM/EDS}

Clearly visible cracks with SEM images and abundant etch pits are the typical dissolution features on olivine grains (Malvoisin et al. 2012; Oelkers et al. 2018). SEM observation revealed these dissolution characteristics on the surface of olivine (Fig. 2). Initial olivine used as the starting material in the heating experiment had angular shapes with smooth surfaces (Fig. 2a, b). Numerous

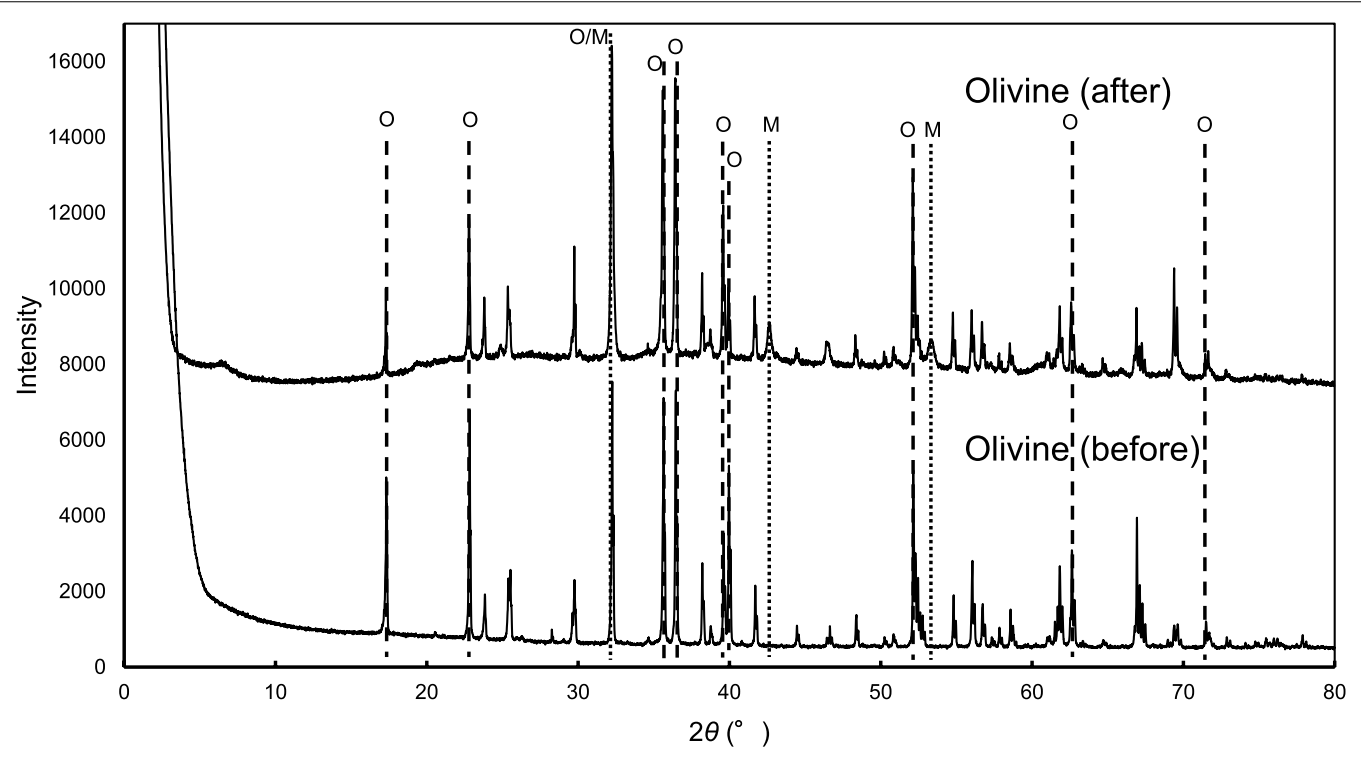

Fig. 1 XRD patterns of olivine before (lower) and after (upper) the experiment. The bulk structure of olivine did not change after heating with organic mixture. New peaks due to magnesite appeared in the XRD pattern of olivine (after). O: Olivine, M: Magnesite 
residual olivine grains after the experiment apparently showed the alteration features. Isolated conical etch pits are shown in Fig. 2c, d (hereafter called grain A) and mammillated topography is shown in Fig. 2e, f (hereafter called grain B). Most of the etch pits detected in this study were conical to polyhedral or pyramidal features.

Precipitation features, which had a webbed structure, covered the surface of the heated grains (Fig. 2c, d). This structure gradually suffered damage during SEM observation, indicating the presence of materials that interact with the electron beam. Irregularly shaped fragile materials of $1-10 \mu \mathrm{m}$ in diameter, likely organic residues, were also on the surface of the olivine (Fig. 2e-h). Such fragile materials were easily damaged by an electron beam, and commonly contained in the experimental product. Details of the changes in the molecular structures of organic mixture during heating experiments and the effects of minerals were published elsewhere (Hirakawa et al. in press).

The chemical composition of olivine obtained by EDS had a 1:2 Si/(Mg+Fe) molar ratio (Additional file 1: Figure S2). Flat surface areas of the grains in the experimental product showed similar compositions as the starting materials, while the areas covered with precipitation features showed Mg-poor and Si-rich compositions. Note that the information depth of SEM/EDS is approximately $1 \mu \mathrm{m}$; however, precipitation layers were $<1 \mu \mathrm{m}$ (Figs. 3, 4 ). Thus, the chemical compositions of the precipitation areas obtained by EDS could be affected by the initial olivine composition.

\section{TEM/EDS}

TEM investigations revealed a change of morphologies near the grain surface areas. Fig. 3 shows a TEM image with elemental mappings of the FIB section taken from the etch pit area shown in Fig. $2 \mathrm{~g}$, h. A matrix of flakelike particles constituting an anastomosing network was observed in this area. $\mathrm{C}$ was entirely distributed in the mapping area, while $\mathrm{Si}, \mathrm{O}, \mathrm{Mg}$, and Fe showed an irregular distribution feature. Si was concentrated in the flake-like particles (Fig. 3c). Iron oxides were on the etch pits (Fig. 3e, f). Mg was clearly depleted in the surface area of olivine in Fig. 3 (likely the webbed structure as discussed in section Alteration of olivine); however, there were a few areas concentrated in $\mathrm{Mg}, \mathrm{Si}, \mathrm{O}$, and $\mathrm{Fe}$, which are independent from flake-like particles.
Differences in chemical compositions of these areas were shown in Additional file 1: Figure S3 (Points 1-4). Point 1 was richer in $\mathrm{Mg}$ than the other areas; however, the mineral phase was not identified. Point 2 and Point 3 were flake-like particles, and these chemical compositions were plotted between serpentine and talc. Point 4 was the surface area of olivine and its composition was slightly $\mathrm{Mg}$ depleted compared to the initial olivine. Nanoscale spherical black particles shown in Fig. 3a were $\mathrm{Au}$ from the coatings on the surface of grain B for SEM observations. A TEM image of the other area in the FIB section showed tubular fibers $(<100 \mathrm{~nm}$ thick) on the surface of olivine that were anastomosed and were poorly crystalline (Fig. 4). The lattice fringes were unclear and were easily damaged by the electron beam during TEM observation. The electron diffraction spots (Fig. 4) were not clear enough for identifying crystal structure. These features were significantly similar to those of proto-serpentine reported by Lafey et al. (2016), which could be formed in the first step of serpentinization of olivine (Lafay et al. 2012, 2016).

\section{Discussion \\ Alteration of olivine}

It is well known that mineral replacements, such as serpentinization, take place primarily by dissolution-precipitation processes (Putnis 2002; Lafay et al. 2012). Etch pits confirmed by SEM (Fig. 2c-f) on the surface of product grains could be the preferential dissolution features at the first step of serpentinization. The dissolution process was crystallographically controlled (Velvel 2009; Malvoisin et al. 2012; Lafey et al. 2018). Thus, these etch pits became deeper and elongated in the [010] and [001] direction as alteration proceeds (Velvel 2009; Malvoisin et al. 2012). Isolated conical etch pits (Fig. 2c, d) would evolve to a network of polyhedral and pyramidal mounts and ultimately to a mammillated (sawtooth) topography (Fig. 2e, f; Malvoisin et al. 2012). It indicates that the alteration degree in grain $B$ (Fig. 2e, f) is advanced as compared with grain A (Fig. 2c, d).

Olivine dissolution proceeds by the breaking of $\mathrm{Mg}-\mathrm{O}$ bonds and an early rapid reversible exchange of $\mathrm{Mg}$ for protons on the olivine surface, which then liberates the $\mathrm{SiO}_{4}{ }^{4-}$ anions directly into solution in acidic to neutral solution (Luce et al. 1972; Oelker et al. 2018). In contrast, $\mathrm{Si}-\mathrm{O}$ structures preferentially dissolved ahead of cation

\footnotetext{
(See figure on next page.)

Fig. 2 Microstructure of initial olivine grains (a, b), olivine grains after the experiment (grain A: $\mathbf{c}, \mathbf{d}$; grain B: e, $\mathbf{f}$ ), and an FIB section from grain B $(\mathbf{g}, \mathbf{h})$. a, b Typical olivine grains used as the starting materials. These grains had a smooth surface with smaller olivine particles ( $1 \mu \mathrm{m})$ attached to them. c, d Grain A was partially covered with precipitation features. Conical etch pits were also detected. e, $\mathbf{f}$ Grain B was entirely covered with polyhedral etch pits. Irregularly shaped carbonaceous materials (1-10 $\mu \mathrm{m}$, white particles) were attached to the surface. $\mathbf{g}$, $\mathbf{h}$ An FIB section obtained from grain B (red broken area)
} 


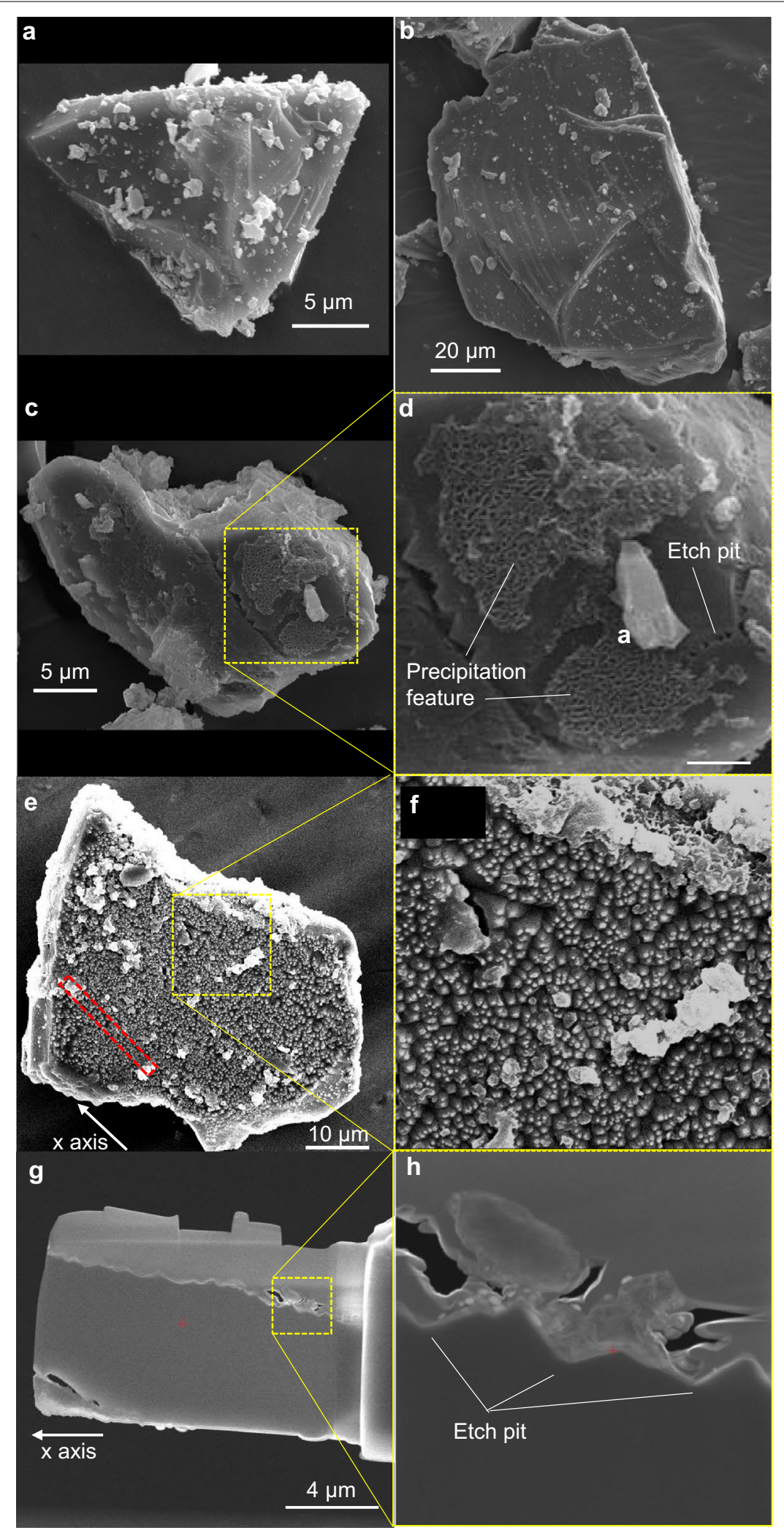




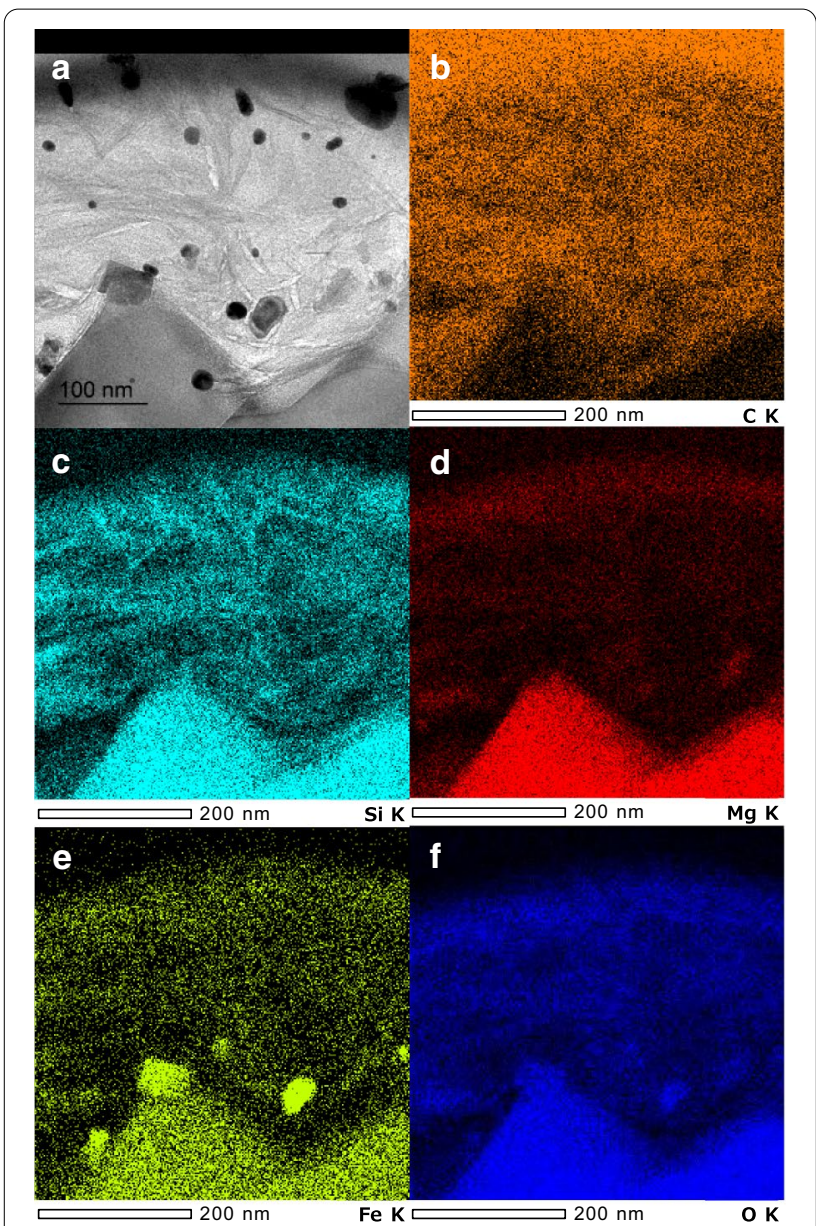

Fig. 3 a A TEM image of the boundary area between etch pits of grain $B$ and a precipitation feature. Flake-like particles can be observed in this area. b-f EDS C, Si, Mg, Fe, and O elemental mappings of the area (a)

dissolution in alkaline solution (Oelker et al. 2018). These processes could result in depletion of $\mathrm{Mg}$ or $\mathrm{Si}$ on the olivine surface. $\mathrm{Mg}$-poor and $\mathrm{Si}$-rich webbed-like structure covering the surface of olivine after the experiments could be precipitation features of dissolved silicate (Lisabeth et al. 2017). Water obtained in an additional experiment through distillation (see Additional file for details) in this study was approximately at $\mathrm{pH}$ 8. Although in situ $\mathrm{pH}$ condition of generated water during heating was not clear in this study, carboxylic acids could contribute to weakly acidic water. Decomposition of amides and hexamethylenetetramine, on the contrary, could generate $\mathrm{NH}_{3}$ (Iwakami et al. 1968), which could result in alkaline water.

Amorphous proto-phyllosilicates precipitated onto the etch pits; thus, growth and crystallization of serpentine or talc proceeded in the precipitation area within or on the etch pits (Plümper et al. 2012). Talc could grow with

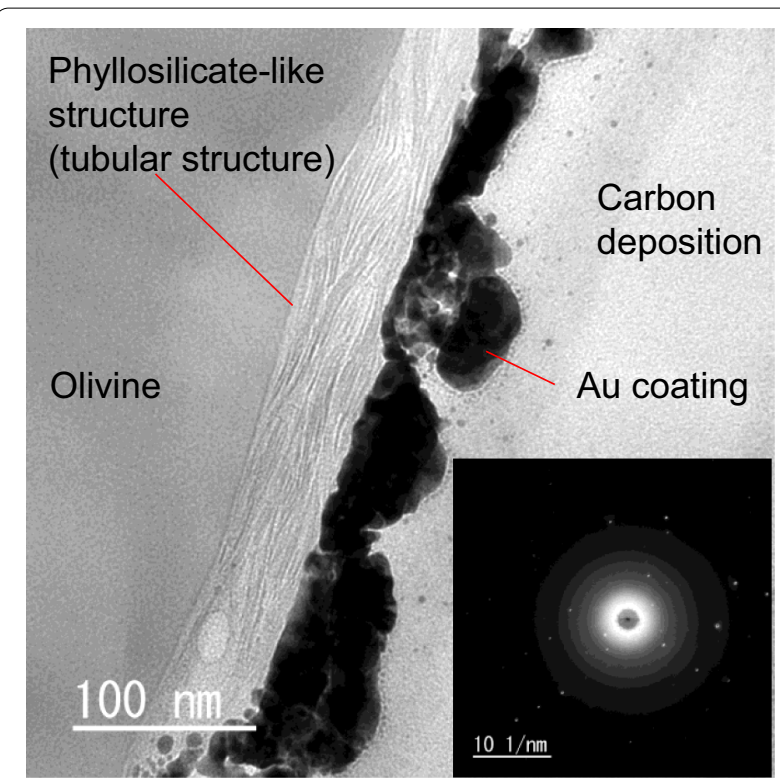

Fig. 4 A TEM image of a phyllosilicate-like structure near the surface area of olivine that had reacted (grain B), along with a diffraction pattern of the structure (lower right). The phyllosilicate-like structure was a tubular anastomosed feature

higher silica activity and $\mathrm{CO}_{2}$ concentration (Moore and Rymer 2007; Oelker et al. 2018). Thus, Si-rich flake-like particles shown in Fig. 3 and tubular fibers shown in Fig. 4 were precipitated features of proto-phyllosilicates, and these features could be the same material for the Mgpoor and Si-rich precipitation features given in Fig. 2c, d. The formation of tubular structures (Fig. 4) also indicated the incipient formation of serpentine or talc on the surface of olivine grains. However, we could not confirm highly crystalline phyllosilicate by electron diffraction because the incomplete crystallization structures resulted in unclear lattice images and electron diffraction spots (Lafey et al. 2016). A schematic image of serpentinization based on obtained characteristics in this study is shown in Fig. 5.

The rate of serpentinization typically depends on temperature, $\mathrm{pH}$, water/rock ratio, and initial grain size (Malvoisin et al. 2012). Reaction progress of serpentinization from olivine with $38-50 \mu \mathrm{m}$ grain size reached nearly $40 \%$ in 250 days at $300{ }^{\circ} \mathrm{C}$, and the major serpentine was lizardite (Malvoisin et al. 2012). Duration of the reaction in this study was 10 days and was likely too short to reach complete serpentinization, although serpentinization rate was the highest at $300{ }^{\circ} \mathrm{C}$ compared with those at higher or lower temperature (Wegner and Ernst 1983; Malvoisin et al. 2012). Yada and Iishi (1974, 1977), however, confirmed the formation of serpentine in shorter time (30 min to 10 days) at $250-400{ }^{\circ} \mathrm{C}$ at 


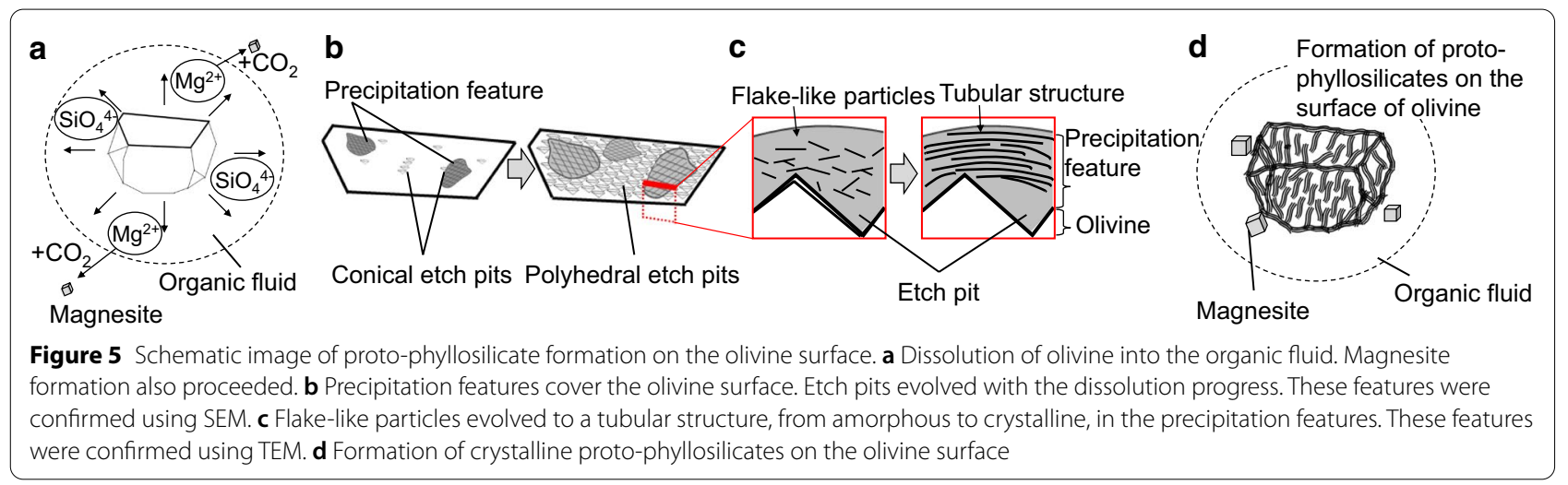

pH 3-13. In that case, conical chrysotile was the major serpentine in fairly wide ranges of $\mathrm{pH}$ and temperature, and lizardite existed at higher temperatures and longer durations. Under the alteration conditions in this study, finding proto-serpentine was reasonable, and it could grow toward chrysotile in several months.

\section{Role of organic matter}

Serpentinization demands water, but water was not present in the starting material in this study. Water, which is required for serpentinization, could be generated through organic reactions, such as dehydration condensation of carboxylic acids and alcohols in the starting material at $300{ }^{\circ} \mathrm{C}$ (Hirakawa et al. in press). Nakano et al. (2020) showed the formation of water from the same organic mixture we used in this study (Additional file 1: Table S1). The amount of water formed depended on the content of hydroxy group ($\mathrm{OH}$ ) of the starting materials (Nakano et al. 2020). Decomposition of these organic compounds could form smaller molecules, such as $\mathrm{CO}, \mathrm{CO}_{2}, \mathrm{CH}_{4}, \mathrm{H}_{2}$, $\mathrm{C}_{2} \mathrm{H}_{6}$, and $\mathrm{C}_{3} \mathrm{H}_{8}$ (Nakano et al. 2003). It is consistent with the generation of $\mathrm{CO}, \mathrm{CO}_{2}, \mathrm{CH}_{4}$, and $\mathrm{H}_{2} \mathrm{O}$ through the destruction of insoluble organic matter in thermally metamorphosed chondrite parent bodies suggested by Alexander et al. (2010). In addition, our previous study showed that decarboxylation was promoted by olivine at $300{ }^{\circ} \mathrm{C}$ (Hirakawa et al. in press). Magnesite, which could be formed via aqueous carbonation of olivine (see details below), as detected by XRD, also indicates the formation of $\mathrm{CO}_{2}$ from the organic mixture.

Phyllosilicates and magnesium carbonate (magnesite) are thermodynamically stable solids in the $\mathrm{MgO}-\mathrm{SiO}_{2}-$ $\mathrm{H}_{2} \mathrm{O}-\mathrm{CO}_{2}$ closed system at $300^{\circ} \mathrm{C}$ and under $1-100$ bar of partial pressure of $\mathrm{CO}_{2}$ (Oelkers et al. 2018). Magnesium olivine (forsterite) favors reactions that form serpentine and magnesite in accordance with

$$
\begin{aligned}
& 2 \mathrm{Mg}_{2} \mathrm{SiO}_{4}+\mathrm{CO}_{2}+2 \mathrm{H}_{2} \mathrm{O} \rightarrow \underset{3}{ } \mathrm{Mg}_{3} \mathrm{Si}_{2} \mathrm{O}_{5}(\mathrm{OH})_{4}+\mathrm{MgCO}_{3} \\
& \text { (Forsterite) }
\end{aligned}
$$

or talc and magnesite in accord with

$$
\begin{aligned}
& 4 \mathrm{Mg}_{2} \mathrm{SiO}_{4}+5 \mathrm{CO}_{2}+\mathrm{H}_{2} \mathrm{O} \rightarrow \underset{\mathrm{Mg}_{3} \mathrm{Si}_{4} \mathrm{O}_{10}(\mathrm{OH})_{2}+5 \mathrm{MgCO}_{3}}{\text { (Forsterite) }} \quad \text { (Talc) } \quad \text { (Magnesite) }
\end{aligned}
$$

under higher $\mathrm{CO}_{2}$ concentration in water (Oelkers et al. 2018). Organic-induced serpentinization is possible with simultaneous water formation from dehydration of organic compounds. It indicates the possibility of in situ formation of phyllosilicates inside the $\mathrm{H}_{2} \mathrm{O}$ snow line because refractory organic compounds, in contrast to $\mathrm{H}_{2} \mathrm{O}$, could survive during accretion of planetesimals in the area, as discussed below.

Water/rock ratio of ordinary chondrites was estimated as $\sim 0.1-0.2$ (Doyle et al. 2015). Water/rock ratios of carbonaceous chondrites were estimated by Marrocchi et al. (2018), the ratio of CM chondrite was 0.4, CR was 0.1$0.4, \mathrm{CV}$ was $0.1-0.2$, and $\mathrm{CO}$ was $0.01-0.10$. Glavin et al. (2018) also summarized the water/rock ratio of carbonaceous chondrites based on Brearley (2006) and Krot et al. (2006), and the ratio of CI was 1.1-1.2, CM was 0.3-0.6, and CR was $0.4-1.1$. Thus, water/rock ratio in this experiment (0.13, see Additional file for details) was consistent with $\mathrm{CV}, \mathrm{CO}$, and ordinary chondrites.

\section{Possible aqueous alteration in the "Dry" parent bodies}

Recent astronomical observations revealed the existence of organic molecules with hydroxy groups, such as $\mathrm{CH}_{3} \mathrm{OH}$ (methanol) (Walsh et al. 2016) and $\mathrm{HCOOH}$ (formic acid) (Favre et al. 2018), in protoplanetary disk, as well as $\mathrm{CH}_{3} \mathrm{CH}_{2} \mathrm{OH}$ (ethanol), $\mathrm{CH}_{3} \mathrm{COOH}$ (acetic acid), and $\mathrm{HOCH}_{2} \mathrm{CHO}$ (glycolaldehyde) were suggested by model calculation (Walsh et al. 2016). $\mathrm{CH}_{3} \mathrm{CH}_{2} \mathrm{OH}$, $\mathrm{CH}_{3} \mathrm{COOH}$, and $\mathrm{HOCH}_{2} \mathrm{CHO}$ were detected from the low-mass protostar IRAS 16293-2422 (Bisschop et al. 2008; Jerry Shiao et al. 2010; Jørgensen et al. 2012). They 
could be delivered inside the snow line on dust particles. Water and highly volatile organic compounds evaporated inside the snow line, but the other organic molecules could remain on the grain surfaces. At least, organic compounds, such as polyaromatic hydrocarbons, aliphatic hydrocarbons, alcohols, carboxylic acids, and macromolecular organics detected in cometary dusts, could survive inside the sublimation area of water ice (Herbst and van Dishoeck 2009; Walsh et al. 2014). In that case, organic matter could accumulate on planetesimals without water or with little water.

Ordinary chondrites originate from S-type asteroids located in the inner region of the asteroid belt inside the snow line. However, some ordinary chondrites show aqueous alteration features. For example, the Semarkona meteorite (LL3.0) has phyllosilicates (Alexander et al. 1989; Piani et al. 2015). The major phyllosilicate phase in Semarkona is smectite, and carbonate is calcium carbonate (Hutchison et al. 1987; Alexander et al. 1989), although proto-phyllosilicates and magnesium carbonate formed in the present study. These differences could be due to the glassy mesostases in Semarkona (Hutchison et al. 1987). The glassy mesostases are highly susceptible to hydration compared with crystalline olivine (Dobrica and Brearley 2020). The total amount of water generated from organic matter could be much less than that present in aqueously altered carbonaceous chondrite parent bodies. Thus, in the case of Semarkona, the small amount of water generated from organic matter could contribute to dissolution of glassy mesostases and some metal ions from the other minerals to form smectite and calcium carbonate (Hutchison et al. 1987), preceding the dissolution of olivine. In addition, the Semarkona parent body could have heterogeneous textures with variable porosity (Dobrica and Brearley 2020), and thus, water could move through the grain boundaries, while the alteration condition in our experiment was static with only one mineral (olivine) in a closed system.

Water abundance in the bulk Semarkona was estimated as $0.2-0.7$ wt.\% (Alexander et al. 2010). Assuming that primordial organic matter accumulated in the Semarkona parent body was similar to the organic mixture used in this study, at least $8-28$ wt.\% of organic matter has to initially present in the parent body necessary for producing the amount of water in Semarkona, since the water produced from the organic mixture was $2.5 \mathrm{wt} . \%$ (see Additional file for details). Organic carbon in the bulk Semarkona meteorite as insoluble organic matter is 0.36 wt.\% (Alexander et al. 2007), thus, if the water was delivered from organics, some of organic matter should have been lost through subsequent thermal processes.

The results in the present study indicate that the hydration of anhydrous silicate was possible in their parent bodies with organic matter at least locally, even if water ice did not accumulate on them. However, there could be some differences in conditions between parent bodies and the experiment-such as mineral compositions and static/flow of water, and thus, further studies are needed to evaluate the details of such alteration processes. Some thermally metamorphosed chondrites classified in $\mathrm{CV}$ and $\mathrm{CO}$ chondrites with alteration features could have captured water near, or in some case inside, the snow line (Marrocchi et al. 2018); thus, the role of organic matter to generate water to produce hydrated silicates would be minor. The water generated from organic matter could significantly contribute to alteration of anhydrous minerals, only in case of the accretion inside the snowline.

Our results further implied that organic matter was one of the possible sources of deuterium-rich water in ordinary chondrites. For example, water in $\mathrm{CM}$ chondrites are homogeneously D poor (Alexander et al. 2012). The water could have originated from isotopic re-equilibration in the inner disk between gaseous $\mathrm{H}_{2} \mathrm{O}$ and the D-depleted solar $\mathrm{H}_{2}$ (Jacquet and Robert 2013). In contrast to these, the $\mathrm{D} / \mathrm{H}$ ratios of water in ordinary chondrites are highly heterogeneous (Alexander et al. 2017). Some of them show significantly high $\mathrm{D} / \mathrm{H}$ ratios, similar to some comets (Piani et al. 2015). The existence of D-rich water in ordinary chondrites was explained by an oxidation reaction of Fe metal $\left(3 \mathrm{Fe}+4 \mathrm{H}_{2} \mathrm{O}=\mathrm{Fe}_{3} \mathrm{O}_{4}+4 \mathrm{H}_{2}\right.$; Alexander et al. 2010, 2017). Loss of isotopically light $\mathrm{H}_{2}$ gas would have enriched the residual water in deuterium (Alexander et al. 2017). Piani et al. (2015), however, pointed out that the process would have required a large amount of initial water and a significant amount of oxidation reactions to explain the high $\mathrm{D} / \mathrm{H}$ values. They suggested that the $\mathrm{D}$-rich water could originate from isotopically heterogeneous ice inherited from the interstellar ice (Piani et al. 2015). Alternatively, Remusat et al. (2016) suggested that the D-rich, recalcitrant organic matter in some ordinary chondrites could be interstellar origin. In addition to these hypotheses, Nakano et al. (2020) suggested that precometary organic matter could be another water source in ordinary chondrite parent bodies. High deuterium concentration in organic matter is well known in the interstellar medium (ISM) and the outer region of the Solar System (Owen et al. 1986; Mauersberger et al. 1988; Cecilia 2002; Parise et al. 2004). These organic molecules could be enriched in deuterium by ion molecular reaction (Millar 2003) in the gas phase and/or by grain surface reactions in molecular clouds (Parise et al. 2004; Watanabe and Kouchi 2008; Taquet et al. 2012). Thus, some organic matter could survive the inner region of the solar nebula (Walsh et al. 2014). Although deuterium tends to concentrate on methyl or ethyl group more than on hydroxy groups in alcohols in molecular clouds 
(Nagaoka et al. 2005; Oba et al. 2016), deuterated molecules, such as $\mathrm{CH}_{3} \mathrm{OD}$, were confirmed in ISM (Mauersberger et al. 1988). Thus, both D-poor and D-rich water could be generated from hydroxy groups in organic matter, and such water could then contribute to both D-rich and D-poor hydrated minerals, as well as explain the heterogeneous $\mathrm{D} / \mathrm{H}$ distribution in ordinary chondrites. Further studies are needed to understand the $\mathrm{D} / \mathrm{H}$ fractionation between organic matter and phyllosilicates. In addition, organic matter in ordinary chondrites is generally ${ }^{15} \mathrm{~N}$-poor as compared with ${ }^{15} \mathrm{~N}$-rich organic matter in the outer Solar System. However, nitrogen abundances in ordinary chondrites are small, and ${ }^{15} \mathrm{~N}$-rich organic matter may be preferentially removed during thermal metamorphism (Alexander et al. 1998).

\section{Conclusions}

To investigate the possible hydration of anhydrous silicates by organic matter in meteorite parent bodies, we performed a heating experiment using olivine with precometary organic matter analog. In situ formation of proto-phyllosilicates was confirmed on the surface of reacted olivine. This result implies that organic-induced alteration of silicates was a possible reaction process in "dry" meteorite parent bodies that accreted inside the $\mathrm{H}_{2} \mathrm{O}$ snow line with delivery of organic compounds with hydroxyl groups and without water ice onto them, although additional works will be needed to evaluate different conditions in the future. Alteration characteristics in some ordinary chondrites could be partially derived from these processes. In that case, significantly heterogeneous $\mathrm{D} / \mathrm{H}$ distribution and highly $\mathrm{D}$-rich water in ordinary chondrites could also explained by the production of water from D-rich organic matter.

\section{Supplementary information}

The online version contains supplementary material available at https://doi. org/10.1186/s40623-020-01352-6.

Additional file 1.Additional table, figures, and an additional experiment to estimate the amount of generated water and the $\mathrm{pH}$.

\section{Abbreviations}

XRD: X-ray diffraction; SEM: Scanning electron microscope; EDS: Energy-dispersive X-ray spectrometer; FIB: Focused ion beam; TEM: Transmission electron microscope.

\section{Acknowledgements}

The authors appreciate the constructive comments from two anonymous reviewers. They would like to thank Dr. Shungo Kawagata for providing access to the SEM/EDS equipment, Dr. Aiko Nakato for supporting the FIB processing, Mr. Takamichi Miyazaki for supporting the TEM analysis, and Dr. George D. Cody for providing olivine. We thank Astromaterials Science Research Group (ASRG) for the use of the FIB facility.

\section{Authors' contributions}

$\mathrm{NH}$ conducted the experiments, performed XRD and SEM analyses, and interpreted the data, under the supervisions of YK and KK. NH wrote the manuscript with help from YK. YF and MK performed TEM analyses. All the authors contributed to final manuscript. All the authors read and approved the final manuscript.

\section{Funding}

This research was supported by the Japan Society for the Promotion of Science KAKENHI (Grant Numbers JP17H06458, JP18K03722, and JP19H05073), the Sasakawa Scientific Research Grant from The Japan Science Society (Grant Number 2020-6037), and the Research Scholarship for Young Scientists in the Graduate School of Engineering Science, Yokohama National University.

\section{Availability of data and materials}

The datasets in this study are available from the corresponding author on reasonable request.

\section{Ethics approval and consent to participate}

Not applicable.

\section{Consent for publication \\ Not applicable.}

\section{Competing interests}

The authors declare that they have no competing interests.

\section{Author details}

${ }^{1}$ Graduate School of Engineering Science, Yokohama National University, 79-5 Tokiwadai, Hodogaya-ku, Yokohama 240-8501, Japan. ${ }^{2}$ Department of Earth Science, Tohoku University, 6-3 Aza-aoba, Aramaki, Aoba-ku, Sendai 980-8578, Japan. ${ }^{3}$ Instrumental Analysis Center, Yokohama National University, 79-5 Tokiwadai, Hodogaya-ku, Yokohama 240-8501, Japan. ${ }^{4}$ Faculty of Culture and Sport Policy, Toin University of Yokohama, 1614 Kurogane-cho, Aoba-ku, Yokohama 225-8503, Japan.

Received: 27 July 2020 Accepted: 28 December 2020

Published online: 11 January 2021

\section{References}

Alexander CMOD, Barber DJ, Hutchison R (1989) The microstructure of Semarkona and Bishunpur. Geochim Cosmochim Acta 53:3045-3057. https://doi.org/10.1016/0016-7037(89)90180-4

Alexander CMOD, Russell SS, Arden JW, Ash RD, Grady MM, Pillinger CT (1998) The origin of chondritic macromolecular organic matter: A carbon and nitrogen isotope study. Meteorit Planet Sci 333:603-622. https://doi. org/10.1111/j.1945-5100.1998.tb01667.x

Alexander CMOD, Fogel M, Yabuta H, Cody GD (2007) The origin and evolution of chondrites recorded in the elemental and isotopic compositions of their macromolecular organic matter. Geochim Cosmochim Acta 71:4380-4403. https://doi.org/10.1016/j.gca.2007.06.052

Alexander CMOD, Newsome SD, Fogel ML, Nittler LR, Busemann H, Cody GD (2010) Deuterium enrichments in chondritic macromolecular materialImplications for the origin and evolution of organics, water and asteroids. Geochim Cosmochim Acta 74:4417-4437. https://doi.org/10.1016/j. gca.2010.05.005

Alexander CMOD, Bowden R, Fogel ML (2012) The provenances of asteroids, and their contributions to the volatile inventories of the terrestrial planets. Science 337:721-726. https://doi.org/10.1126/science.1223474

Alexander CMO'D, (2017) The origin of inner Solar System water. Phylos Trans R Soc B-Biol Science A 375:20150384. https://doi.org/10.1098/ rsta.2015.0384

Beitz E, Blum J, Parisi MG, Trigo-Rodríguez JM (2016) The collisional evolution of undifferentiated asteroids and the formation of chondritic meteoroids. Astrophys J 824:12. https://doi.org/10.3847/0004-637X/824/1/12

Bischoff A (1998) Aqueous alteration of carbonaceous chondrites: evidence for preaccretionary alteration-A review. Meteorit Planet Sci 33:1113-1122. https://doi.org/10.1111/j.1945-5100.1998.tb01716.x 
Bisschop SE, Jørgensen JK, Bourke TL, Bottinelli S, van Dishoeck EF (2008) An interferometric study of the low-mass protostar IRAS 16293-2422: small scale organic chemistry. Astron Astrophys 488:959-968. https://doi. org/10.1051/0004-6361:200809673

Brearley AJ (2006) The action of water. In: Lauretta DS, McSween HY (eds) Meteorites and the Early Solar System II. Univ. Arizona Press, Tucson, pp 587-624

Buseck PR, Hua X (1993) Matrices of carbonaceous chondrite meteorites. Ann Rev Earth Plant Sci 21:255-305. https://doi.org/10.1146/annur ev.ea.21.050193.001351

Cecilia C (2002) Millimeter and infrared observations of deuterated molecules. Planet Space Sci 50:1267-1273. https://doi.org/10.1016/S0032 $-0633(02) 00093-4$

Dobrica E, Brearley AJ (2020) Amorphous silicates in the matrix of Semarkona: the first evidence for the localized preservation of pristine matrix materials in the most unequilibrated ordinary chondrites. Meteorit Planet Sci 55:649-668. https://doi.org/10.1111/maps.13458

Doyle PM, Jogo K, Nagashima K, Krot AN, Wakita S, Ciesla FJ, Hucheon ID (2015) Early aqueous activity on the ordinary and carbonaceous chondrite parent bodies recorded by fayalite. Nat Commun 6:7444. https://doi. org/10.1038/ncomms8444

Favre C, Fedele D, Semenov D, Parfenov S, Codella C, Ceccarelli C, Bergin EA, Chapillon E, Testi L, Hersant F (2018) First detection of the simplest organic acid in a protoplanetary disk. Astrophys J 862:L2-9. https://doi. org/10.3847/2041-8213/aad046

Fuchida S, Naraoka H, Masuda H (2017) Formation of diastereoisomeric piperazine-2,5-dione from $\mathrm{DL}$-alanine in the presence of olivine and water. Orig Life Evol Biosph 43:83-92. https://doi.org/10.1007/s11084-016-9500-7

Hirakawa N, Kebukawa Y, Kobayashi K, Nakano H (2020) Effects of minerals on metamorphism of organic matter during thermal processes in meteorite parent bodies. Icarus. https://doi.org/10.1016/j.icarus.2020.114167 (In press)

Herbst E, van Dishoeck EF (2009) Complex organic interstellar molecules. Ann Rev Astron Astrophys 47:427-480. https://doi.org/10.1146/annurev-astro -082708-101654

Huss GR, Rubin EA, Grossman JN (2006) Thermal metamorphism in chondrites. In: Lauretta DS, McSween HY (eds) Meteorites and the Early Solar System II. Univ. Arizona Press, Tucson, pp 567-586

Hutchison R, Alexander CMOD, Barber DJ (1987) The Semarkona meteorite: First recorded occurrence of smectite in an ordinary chondrite, and its implications. Geochim Cosmochim Acta 51:1875-1882. https://doi. org/10.1016/0016-7037(87)90178-5

Iwakami Y, Takazono M, Tsuchiya T (1968) Thermal decomposition of hexamethylene tetramine. Bull Chem Soc Jpn 41:813-817. https://doi. org/10.1246/bcsj.41.813

Jacquet E, Robert F (2013) Water transport in protoplanetary disks and the hydrogen isotopic composition of Chondrites. Icurus 2:722-732. https:// doi.org/10.1016/j.icarus.2013.01.022

Jerry Shiao YS, Looney LW, Remijan AJ, Snyder LE, Friedel DN (2010) First acetic acid survey with CARMA in hot molecular cores. Astrophys J 716:286. https://doi.org/10.1088/0004-637X/716/1/286

Jørgensen JK, Favre C, Bisschop SE, Bourke TL, van Dishoeck EF, Schmalzl M (2012) Detection of the simplest sugar, glycolaldehyde, in a solar-type protostar with ALMA. Astrophys J Lett 757:L4. https://doi. org/10.1088/2041-8205/757/1/L4

Kebukawa Y, Nakashima S, Zolensky ME (2010) Kinetics of organic matter degradation in the Murchison meteorite for the evaluation of parent-body temperature history. Meteorit Planet Sci 45:99-113. https://doi.org/10.11 11/j.1945-5100.2009.01008.x

King AJ, Schofield PF, Russell SS (2017) Type 1 aqueous alteration in CM carbonaceous chondrites: implications for the evolution of water-rich asteroids. Meteorit Planet Sci 52:1197-1215. https://doi.org/10.1111/maps.12872

Kitajima F, Nakamura T, Takaoka N, Marue T (2002) Evaluating the thermal metamorphism of CM chondrites by using the pyrolytic behavior of carbonaceous macromolecular matter. Geochim Cosmochim Acta 66:163-172. https://doi.org/10.1016/S0016-7037(01)00758-X

Kouchi A, Kudo T, Nakano H, Arakawa M, Watanabe N (2002) Rapid growth of asteroids owing to very sticky interstellar organic grains. Astrophys J 566:L121-124. https://doi.org/10.1086/339618

Lafay R, Montes-Hernandez G, Janots E, Chiriac R, Findling N, Toche F (2012) Mineral replacement rate of olivine by chrysotile and brucite under high alkaline conditions. J Cryst Growth 347:62-72. https://doi.org/10.1016/j. jcrysgro.2012.02.040

Lafey R, Montes-Hernandez G, Janots E, Chiriac R, Findling N, Toche F (2014) Simultaneous precipitation of magnesite and lizardite from hydrothermal alteration of olivine under high-carbonate alkalinity. Chem Geol 368:63-75. https://doi.org/10.1016/j.chemgeo.2014.01.008

Lafey R, Fernandez-Martinez J, Montes-Hernandez G, Auzende AL, Poulain A (2016) Dissolution-reprecipitation and self-assembly of serpentine nanoparticles preceding chrysotile formation: Insights into the structure of proto-serpentine. Am Mineral 101:2666-2676. https://doi.org/10.2138/ am-2016-5772

Lisabeth H, Zhu W, Xing T, De Andrade V (2017) Dissolution-assisted pattern formation during olivine carbonation. Geophys Res Lett 44:9622-9631. https://doi.org/10.1002/2017GL074393

Luce RW, Bartlett RW, Parks GA (1972) Dissolution kinetics of magnesium silicates. Geochim Cosmochim Acta 36: 35-50. https://ui.adsabs.harva rd.edu/abs/1972GeCoA..36...35L/abstract

Malvoisin B, Brunet F, Carlut J, Rouméjon S, Cannat M (2012) Serpentinization of oceanic peridotites: 2. Kinetics and processes of San Carlos olivine hydrothermal alteration. J Geophys Res Solid Earth 117:B04102. https:// doi.org/10.1029/2011 JB008842

Marrocchi Y, Bekaert DV, Piani L (2018) Origin and abundance of water in carbonaceous asteroids. Earth Planet Sci Lett 482:23-32. https://doi. org/10.1016/j.epsl.2017.10.060

Mauersberger R, Henkel C, Jacq T, Walmsley CM (1988) Deuterated methanol in Orion. Astron Astrophys 194:L1-4

Millar TJ (2003) Deuterium fractionation in interstellar clouds. Space Sci Rev 106:73. https://doi.org/10.1023/A:1024677318645

Moore DE, Rymer MJ (2007) Talc-bearing serpentinite and the creeping section of the San Andreas fault. Nature 448:795-797. https://doi.org/10.1038/ nature06064

Nagaoka A, Watanabe N, Kouchi A (2005) H-D substitution in interstellar solid methanol: a key route for D enrichment. Astrophys J 624:L29-32. https:// doi.org/10.1086/430304

Nakamura T (2005) Post-hydration thermal metamorphism of carbonaceous chondrites. J Miner Petrol Sci 100:260-272. https://doi.org/10.2465/ jmps.100.260

Nakano H, Kouchi A, Arakawa M, Kimura Y, Kaito C, Ohno H, Hondoh T (2002) Alteration of interstellar organic materials in meteorites' parent bodies: a novel route for diamond formation. Proc Jpn Acad. Ser. B 78:277-281. https://doi.org/10.2183/pjab.78.277

Nakano H, Kouchi A, Tachibana S, Tsuchiyama A (2003) Evaporation of interstellar organic materials in the solar nebula. Astrophys J 592:1252-1262. https://doi.org/10.1086/375856

Nakano H, Hirakawa N, Matsubara Y, Yamashita S, Okuchi T, Asahina K, Tanaka R, Suzuki N, Naraoka H, Takano Y, Tachibana S, Hama T, Oba Y, Kimura Y, Watanabe N, Kouchi A (2020) Precometary organic matter: a hidden reservoir of water inside the snow line. Sci Rep 10:7755. https://doi. org/10.1038/s41598-020-64815-6

Nakato A, Nakamura T, Kitajima F, Noguchi T (2008) Evaluation of dehydration mechanism during heating of hydrous asteroids based on mineralogical and chemical analysis of naturally and experimentally heated CM chondrites. Earth Planet Sci 60:855-864. https://doi.org/10.1186/BF03352837

Oba Y, Osaka K, Chigai T, Kouchi A, Watanabe N (2016) Hydrogen-deuterium substitution in solid ethanol by surface reactions at low temperatures. Mon Notices Royal Astron Soc 462:689-695. https://doi.org/10.1093/ mnras/stw1714

Oelkers EH, Declercq J, Saldi GD, Gislason SR, Schott J (2018) Olivine dissolution rates: a critical review. Chem Geol 500:1-19. https://doi. org/10.1016/j.chemgeo.2018.10.008

Owen T, Lutz BL, de Bergh C (1986) Deuterium in the outer Solar System: evidence for two distinct reservoirs. Nature 320:244-246. https://doi. org/10.1038/320244a0

Parise B, Castets A, Herbst E, Caux E, Ceccarelli C, Mukhopadhyay I, Tielens AGGM (2004) First detection of triply-deuterated methanol. Astron Astrophys 416:159-163. https://doi.org/10.1051/0004-6361:20034490

Pearson VK, Sephton M, Kearsley AT, Bland PA, Franchi IA, Gilmour I (2002) Clay mineral-organic matter relationships in the early solar system. Meteorit Planet Sci 37:1829-1833. https://doi.org/10.1111/j.1945-5100.2002.tb011 66.x 
Piani L, Robert F, Remusat L (2015) Micron-scale D/H heterogeneity in chondrite matrices: a signature of the pristine solar system water? Earth Planet Sci Lett 415:154-164. https://doi.org/10.1016/j.epsl.2015.01.039

Plümper O, Royne A, Magraso A, Jamtveit B (2012) The interface-scale mechanism of reaction-induced fracturing during serpentinization. Geol 40:1103-1106. https://doi.org/10.1130/G33390.1

Putnis A (2002) Mineral replacement reactions: from macroscopic observations to microscopic mechanisms. Mineral Mag 66:689-708. https://doi. org/10.1180/0026461026650056

Quirico E, Bonal L, Beck P, Alexander CMO'D, Yabuta H, Nakamura T, Nakato A, Flandinet L, Montagnac G, Schmitt-Kopplin P, Herd CDK, (2018) Prevalence and nature of heating processes in CM and C2-ungrouped chondrites as revealed by insoluble organic matter. Geochim Cosmochim Acta 241:17-37. https://doi.org/10.1016/j.gca.2018.08.029

Remsat L, Piani L, Bernard S (2016) Thermal recalcitrance of the organic D-rich component of ordinary chondrites. Earth Planet Sci Lett 435:36-44. https ://doi.org/10.1016/j.epsl.2015.12.009

Rotelli L, Trigo-Rodríguez JM, Moyano-Cambero CE, Carota E, Botta L, Di Mauro E, Saladino R (2016) The key role of meteorites in the formation of relevant prebiotic molecules in a formamide/water environment. Sci Rep 6:38888. https://doi.org/10.1038/srep38888

Rubin AE, Trigo-Rodríguez JM, Huber H, Wasson JT (2007) Progressive aqueous alteration of CM carbonaceous chondrites. Geochim Chosmochim Acta 71:2361-2382. https://doi.org/10.1016/j.gca.2007.02.008

Taquet V, Ceccarelli C, Kahane C (2012) Formaldehyde and methanol deuteration in protostars: fossils from a past fast high-density Pre-collapse phase. Astrophys J Lett 748:L3. https://doi.org/10.1088/2041-8205/748/1/L3

Tomeoka K, Tanimura I (2000) Phyllosilicate-rich chondrule rims in the Vigarano CV3 chondrite: evidence for parent-body processes. Geochimica et Cosmochimica Acta. 64:1971-1988. https://doi.org/10.1016/S0016 $-7037(00) 00332-X$

Trigo-Rodríguez JM, Rubin AE, Wasson JT (2006) Non-nebular origin of dark mantles around chondrules and inclusions in CM chondrites. Geochimica et Cosmochimica Acta 70:1271-1290. https://doi.org/10.1016/j. gca.2005.11.009

Trigo-Rodríguez JM, Rimola A, Tanbakouei S, Soto VC, Lee M (2019) Accretion of Water in carbonaceous chondrites: current evidence and implications for the delivery of water to early earth. Space Sci Rev 215:18. https://doi. org/10.1007/s11214-019-0583-0

Ulrich M, Muñoz M, Guillot S, Cathelineau M, Picard C, Quesnel B, Boulvais P, Couteau C (2014) Dissolution-precipitation processes governing the carbonation and silicification of the serpentinite sole of the New Caledonia ophiolite. Contrib to Mineral Petrol 167:952. https://doi.org/10.1007/ s00410-013-0952-8
Velvel MA (2009) Dissolution of olivine during natural weathering. Geochim Cosmochim Acta 73:6098-6113. https://doi.org/10.1016/j. gca.2009.07.024

Vinogradoff V, Le Guillou C, Bernard S, Viennet JC, Jaber M, Remusat L (2020) Influence of phyllosilicates on the hydrothermal alteration of organic matter in asteroids: experimental perspectives. Geochim Cosmochim Acta 269:150-166. https://doi.org/10.1016/j.gca.2019.10.029

Vinogradoff V, Remusat L, McLain HL, Aponte JC, Bernard S, Danger G, Dworkin JP, Elsila JE, Jaber M (2020) Impact of phyllosilicates on amino acid formation under asteroidal conditions. ACS Earth Space Chem 4:1398-1407. https://doi.org/10.1021/acsearthspacechem.0c00137

Walsh C, Millar TJ, Nomura H, Herbst E, Weaver SW, Aikawa Y, Laas JC, Vasyunin Al (2014) Complex organic molecules in protoplanetary disks. Astron Astrophys 563:A33. https://doi.org/10.1051/0004-6361/201322446

Walsh C, Loomis RA, Öberg Kl, Kama M, Hoff MLR, Millar TJ, Aikawa Y, Herbst E, Weaver SLW, Nomura H (2016) First detection of gas-phase methanol in a protoplanetary disk. Astrophys J Lett 823:L10. https://doi. org/10.3847/2041-8205/823/1/L10

Watanabe N, Kouchi A (2008) Ice surface reactions: a key to chemical evolution in space. Prog Surf Sci 83:439-489. https://doi.org/10.1016/j.progs urf.2008.10.001

Wegner WW, Ernst WG (1983) Experimentally determined hydration and dehydration reaction rates in the system $\mathrm{MgO}-\mathrm{SiO}_{2}-\mathrm{H}_{2} \mathrm{O}$. Am J Sci 283-A: 151-180.

Yada K, lishi K (1974) Serpentine minerals hydrothermally synthesized and their microstructures. J Cryst Growth 24(25):627-630. https://doi. org/10.1016/0022-0248(74)90393-5

Yada K, lishi K (1977) Growth and microstructure of synthetic chrysotile. Am Mineral 62:958-965

Yamashita Y, Naraoka H (2014) Two homologous series of alkylpyridines in the Murchison meteorite. Geochem J 48:519-525. https://doi.org/10.2343/ geochemj.2.0340

\section{Publisher's Note}

Springer Nature remains neutral with regard to jurisdictional claims in published maps and institutional affiliations.

\section{Submit your manuscript to a SpringerOpen ${ }^{\circ}$ journal and benefit from:}

- Convenient online submission

- Rigorous peer review

- Open access: articles freely available online

- High visibility within the field

- Retaining the copyright to your article

Submit your next manuscript at $\boldsymbol{\nabla}$ springeropen.com 